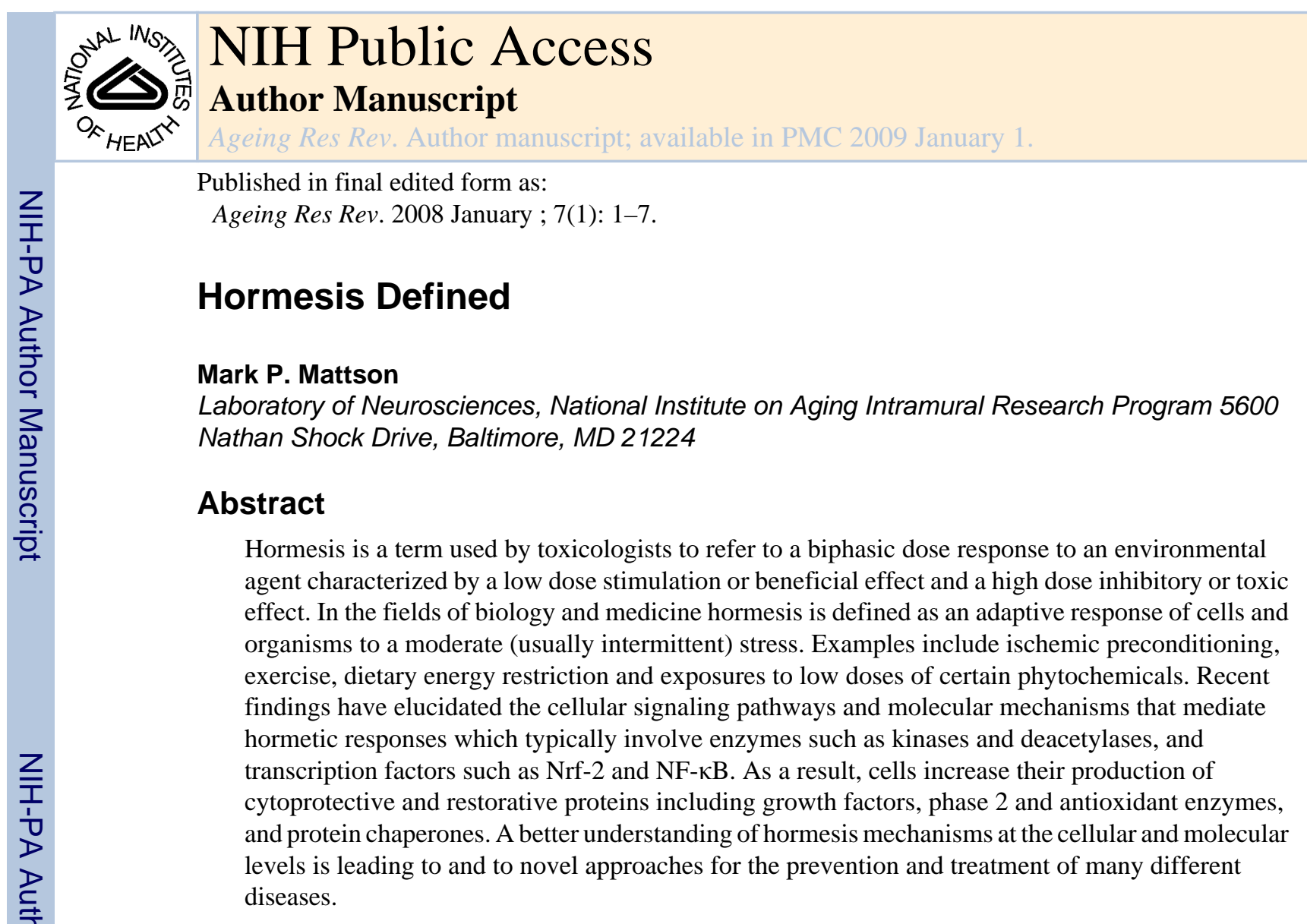

\title{
Keywords
}

adaptive stress response; exercise; histone deacetylase; phytochemicals; preconditioning; toxic

\section{The Concept of Hormesis}

The term hormesis (see Calabrese et al., 2007 for a detailed consideration of the definition and uses of hormesis) has been most widely used in the toxicology field where investigators use it to describe a biphasic dose response with a low dose stimulation or beneficial effect and a high dose inhibitory or toxic effect. The response of the cell or organism to the low dose of the toxin is considered an adaptive compensatory process following an initial disruption in homeostasis. Thus, a short working definition of hormesis is: 'a process in which exposure to a low dose of a chemical agent or environmental factor that is damaging at higher doses induces an adaptive beneficial effect on the cell or organism'. The prevalence in the literature of hormetic dose responses to environmental toxins has been reviewed comprehensively (Calabrese and Blain, 2005), as have the implications of toxin-mediated hormesis for understanding carcinogenesis and its prevention (Calabrese, 2005). Several different terms are commonly used to describe specific types of hormetic responses including "preconditioning" and "adaptive stress response".

While hormesis is most often thought of in the context of exposures to exogenous agents or environmental conditions, it should also be recognized that hormesis is integral to the normal

Correspondence: Mark P. Mattson. Email: mattsonm@grc.nia.nih.gov.

Publisher's Disclaimer: This is a PDF file of an unedited manuscript that has been accepted for publication. As a service to our customers we are providing this early version of the manuscript. The manuscript will undergo copyediting, typesetting, and review of the resulting proof before it is published in its final citable form. Please note that during the production process errors may be discovered which could affect the content, and all legal disclaimers that apply to the journal pertain. 
physiological function of cells and organisms. For example, exposure of neurons to the excitatory neurotransmitter glutamate during their normal activity results in energetic and oxidative stress accompanied by activation of hormetic pathways that help the neurons cope with more severe stress; however, excessive activation of glutamate receptors can kill neurons in a process called excitotoxicity (Mattson, 2003). As an introduction to this special issue of Ageing Research Reviews (ARR), this article presents several examples of hormesis and their implications for health and disease. In another article in this issue, Ed Calabrese presents his views of hormesis an overarching concept in the fields of toxicology, biology and medicine (Calabrese, 2007).

Hormesis is a fundamental concept in evolutionary theory. From the beginning through the present time, life on earth has existed in harsh environments in which cells are often exposed to free radicals and toxic substances. To avoid extinction organisms have developed complex mechanisms to cope with the environmental hazards. Typically, such hormetic response pathways involve proteins such as ion channels, kinases and deacetylases, and transcription factors which regulate the expression of genes that encode cytoprotective proteins. Several major categories of hormetic stress resistance proteins have been identified including protein chaperones such as the heat-shock proteins, antioxidant enzymes such as superoxide dismutases and glutathione peroxidase, and growth factors such as insulin-like growth factors and brain-derived neurotrophic factor (Mathers et al., 2004; Mattson et al., 2004; Young et al., 2004; Cuervo, 2007; Staud, 2007). In some cases organisms have harnessed the chemical properties of "toxic agents", incorporating them into cellular signaling or metabolic pathways. Examples include oxygen (critical for respiration), carbon monoxide (serves as a signaling molecule in neurons), iron and selenium (potentially toxic metals that are critical for the function of many different enzymes).

\section{The Biphasic Dose-Response is a Fundamental Feature of Hormesis}

Thousands of published articles include data showing biphasic responses of cells or organisms to chemicals or changing environmental conditions. Calabrese et al. have published numerous meta-analysis that catalog many examples of such hormetic dose response curves (Calabrese and Baldwin, 1999, 2001). While not all toxic factors may induce a biphasic dose response in cells and organisms, many clearly do. Examples include many chemicals, temperature, radiation, exercise, energy intake and others. A biphasic dose response curve from work done in my laboratory more than a decade ago is shown in Figure 2. In this example, low concentrations of the lipid mediator ceramide protected cultured brain nerve cells from being killed by a high concentration of the excitatory neurotransmitter glutamate; on the other hand, high concentrations of ceramide were toxic to the neurons (Goodman and Mattson, 1996). Interestingly, glutamate itself can induce hormesis, as pretreatment of neurons with a low concentration of glutamate can protect them from being damaged by a higher concentration of glutamate (Marini et al., 2007). Naturally occurring environmental neurotoxins may also exert neuroprotective effects when administered at low doses, as discussed by Ann Marini in this issue of ARR (Marini, 2007).

One of the most widely studied types of experimental hormesis, called preconditioning ischemia, occurs when an organ (the heart or brain, for example) are subjected to a brief mild ischemia. Having been exposed to the mild ischemia the cells become resistant to being killed by a full-blown heart attack or stroke (Yellon and Downey, 2003; Pong, 2004). Ischemia exhibits a biphasic dose response, with brief periods of ischemia being protective and prolonged periods resulting in cell damage. The cellular and molecular mechanisms underlying preconditioning ischemia hormesis are being elucidated and may involve oxidative stressinduced cytoprotective signaling pathways involving activation of kinases, changes in mitochondria, and the expression of genes encoding antioxidant enzymes and protein 
chaperones (Juhaszova et al., 2004). In this issue of ARR Steve Sollott describes the current state of knowledge concerning mechanisms of conditioning ischemia hormesis (Sollott, 2007).

A common observation in studies of hormesis is that exposure to low levels of one type of hormetic agent can protect cells/organisms against more than one type of stress. For example, exposure of cells to mild heat stress can protect them from being damaged by oxidative stress or toxins such as cyanide (Li et al., 2002). Similarly, when cells are exposed to a low dose of the mitochondrial uncoupling agent 2, 4-dinitrophenol they are less vulnerable to being killed by ischemia (Korde et al., 2005). This "cross-modal" aspect of hormesis in biological systems, may explain the broad benefits of exercise and dietary energy restriction (see below and Mattson, 2007b). Recent findings suggest that health benefits of many phytochemicals may also be conferred by cross-modal hormesis mechanisms in which a phytochemical activates one or more adaptive cellular stress response pathways (Mattson and Cheng, 2006).

\section{Hormesis in Daily Life}

Several articles in this special issue of ARR describe evidence supporting hormesis as a mechanism responsible for the health benefits of a variety of lifestyle and environmental factors. This is best documented for exercise which increases the resistance of musculoskeletal and cardiovascular systems to injury and disease (Kojda and Hambrecht, 2005). But moderate regular exercise also benefits other tissues including the nervous system (Gomezi-Pinilla, 2007) and digestive system (Bi and Triadafilopoulos, 2003). Zsolt Radak and Fernando Gomez-Pinilla cover the current state of knowledge of the hormetic effects exercise on muscle and nerve cells (Gomez-Pinilla, 2007; Radak, 2007). The public in industrialized countries is bombarded with a bewildering array of information on the effects of dietary factors on health (Satia-About a et al., 2002). However, the only well-established means of improving health through diet is maintaining a relatively low caloric intake, as described previously (Masoro, 2005; Martin et al., 2006). An article in this issue of ARR describes the involvement of hormesis mechanisms in the beneficial effects of dietary energy restriction on health, and also highlights emerging evidence supporting a role for hormesis in the health-promoting actions of several widely-studied chemicals in fruits and vegetables (Mattson, 2007).

Accumulating evidence suggests that the reason that regular engagement in intellectual activities is beneficial for the brain (Scarmeas and Stern, 2003) is that it activates hormetic pathways in neurons. Similar to the changes that occur in muscle cells during exercise, neurons engaged in challenging activities are subjected to repeated bouts of calcium influx, free radical production and moderate (aerobic) energetic stress (Mattson et al., 2002; Serrano and Klann, 2004). As a result, transcription factors such as cyclic AMP response element binding protein (CREB) and nuclear factor $\mathrm{\kappa B}$ (NF- $\mathrm{\kappa B})$ are activated (Carlezon et al., 2005; Mattson and Meffert, 2006), and the expression of several major classes of cytoprotective proteins is increased including neurotrophic factors, heat-shock proteins and others (Lazarov et al., 2005). As with other organ systems, exposure of the cells in the nervous system to mild and transient bouts of stress may increase their resistance to the adversities of ageing. Suresh Rattan reviews the role of hormesis mechanisms in modifying the ageing process in this issue of ARR (Rattan, 2007).

\section{Chemical Hormesis: An Explanation for the Health Benefits of Fruits, Vegetables and Some Drugs?}

Thousands of chemicals isolated from plants have been shown to exert effects on animals that are, in many cases, beneficial for health (Raskin et al., 2002; Reddy et al., 2003). Because oxidative stress contributes to the pathogenesis of many major diseases and the ageing process 
(Sohal and Weindruch, 1996; Valko et al., 2004), and because fruits and vegetables contain chemicals that (at high concentrations) exhibit direct free radical-scavenging properties, there has been a heavy emphasis on the hypothesis that it is the antioxidant activity of phytochemicals that is responsible for their health benefits (Bravo, 1998). Indeed, micromolar concentrations of vitamin $\mathrm{E}$ and numerous polyphenols can protect a variety of cells against oxidative stress in cell culture models of cancer, atherosclerosis and neurodegenerative disorders (Barbasta et al., 2002; Butterfield et al., 2002; Kline et al., 2007). However, clinical trials and primary prevention studies of high doses of such antioxidants in humans have been disappointing at best (Riccioni et al., 2007). Because epidemiological data supporting health benefits of consumption of fruits and vegetables are quite strong (Williams and Hord, 2005), and because the relatively low amount of phytochemicals typically consumed is unlikely to achieve direct antioxidant (micromolar) concentrations in cells, there has been considerable interest in understanding the effects and mechanisms of action of the typically consumed low dose (submicromolar) concentrations of phytochemicals.

.... Studies of experimental models of cancer (Soobratee et al., 2006), cardiovascular disease (Wu et al., 2004) and neurodegenerative disorders (Mattson and Cheng, 2006) have provided evidence that at least some phytochemicals exert beneficial effects by activating adaptive stress response signaling pathways. The pathways typically involve the activation of kinases and transcription factors, resulting in increased production of cytoprotective proteins including phase 2 enzymes, antioxidant enzymes, heat-shock proteins, growth factors and proteins involved in the regulation of cellular energy metabolism (Mattson and Cheng, 2006). Examples include: activation of the Nrf-2 (a transcription factor) and its genetic target, the antioxidant response element (ARE) by sulforaphane and curcumin (Lee and Surh, 2005); activation of histone deacetylases and their target FOXO transcription factors by resveratrol (Frescas et al., 2005); and activation of the transient receptor potential (TRP) calcium channels by capsaicin and allicin (Bautista et al., 2005). In many cases, such "noxious" phytochemicals that activate stress response pathways in cells may serve the function of dissuading microorganisms and insects from eating the plant. In the relatively low doses consumed by humans, however, these noxious phytochemicals activate cellular stress response pathways without adversely affecting their function. In this issue of ARR, Fred Alt describes the emerging role of histone deacetylases of the sirtuin family as key mediators of adaptive cellular stress responses (Alt, 2007).

The concept that drugs exert their beneficial effects by hormetic mechanisms of action can be traced to the $16^{\text {th }}$ century and a Swiss chemist and physician called Paracelsus who wrote: "All things are poison and nothing is without poison, only the dose permits something not to be poisonous" (Wikipedia: http://en.wikipedia.org/wiki/Paracelsus). This concept certainly applies to the many drugs that are derived from plants and microorganisms including various treatments for infections, cancers and pain. Even synthetic drugs thought to act on a specific molecular target may exert "off-target" hormetic effects. In this issue of ARR, Walter Stumpf reviews the evidence supporting hormesis as a common mechanism of drug action (Stumpf, 2007). Hormesis is also implicated in the actions of complementary and alternative medicines including acupuncture (Staud and Price, 2006),

\section{Acknowledgements}

Supported by the Intramural Research Program of the National Institute on Aging, NIH. I thank K. C. Alexander for preparing Figure 3.

\section{References}

Alt FW. Sirtuins and cellular stress responses. Ageing Res Rev. 2007this issue 
Barbaste M, Berke B, Dumas M, Soulet S, Delaunay JC, Castagnino C, Arnaudinaud V, Cheze C, Vercauteren J. Dietary antioxidants, peroxidation and cardiovascular risks. J Nutr Health Aging 2002;6:209-223. [PubMed: 11887247]

Bautista DM, Movahed P, Hinman A, Axelsson HE, Sterner O, Hogestatt ED, Julius D, Jordt SE, Zygmunt PM. Pungent products from garlic activate the sensory ion channel TRPA1. Proc Natl Acad Sci USA 2005;102:12248-12252. [PubMed: 16103371]

Bi L, Triadafilopoulos G. Exercise and gastrointestinal function and disease: an evidence-based review of risks and benefits. Clin Gastroenterol Hepatol 2003;1:345-355. [PubMed: 15017652]

Bravo L. Polyphenols: chemistry, dietary sources, metabolism, and nutritional significance. Nutr Rev 1998;56:317-333. [PubMed: 9838798]

Butterfield DA, Castegna A, Drake J, Scapagnini G, Calabrese V. Vitamin E and neurodegenerative disorders associated with oxidative stress. Nutr Neurosci 2002;5:229-239. [PubMed: 12168685]

Calabrese EJ, Baldwin LA. Chemical hormesis: its historical foundations as a biological hypothesis. Toxicol Pathol 1999;27:195-216. [PubMed: 10207984]

Calabrese EJ, Baldwin LA. Hormesis: a generalizable and unifying hypothesis. Crit Rev Toxicol 2001;31:353-424. [PubMed: 11504172]

Calabrese EJ. Cancer biology and hormesis: human tumor cell lines commonly display hormetic (biphasic) dose responses. Crit Rev Toxicol 2005;35:463-582. [PubMed: 16422392]

Calabrese EJ, Blain R. The occurrence of hormetic dose responses in the toxicological literature, the hormesis database: an overview. Toxicol Appl Pharmacol 2005;202:289-301. [PubMed: 15667834]

Calabrese EJ. Converging concepts: adaptive response, preconditioning, and the Yerkes-Dodson law are manifestations of hormesis. Ageing Res Rev. 2007this issue

Calabrese EJ, Bachmann KA, Bailer AJ, Bolger PM, Borak J, Cai L, Cedergreen N, Cherian MG, Chiueh CC, Clarkson TW, Cook RR, Diamond DM, Doolittle DJ, Dorato MA, Duke SO, Feinendegen L, Gardner DE, Hart RW, Hastings KL, Hayes AW, Hoffmann GR, Ives JA, Jaworowski Z, Johnson TE, Jonas WB, Kaminski NE, Keller JG, Klaunig JE, Knudsen TB, Kozumbo WJ, Lettieri T, Liu SZ, Maisseu A, Maynard KI, Masoro EJ, McClellan RO, Mehendale HM, Mothersill C, Newlin DB, Nigg HN, Oehme FW, Phalen RF, Philbert MA, Rattan SI, Riviere JE, Rodricks J, Sapolsky RM, Scott BR, Seymour C, Sinclair DA, Smith-Sonneborn J, Snow ET, Spear L, Stevenson DE, Thomas Y, Tubiana M, Williams GM, Mattson MP. Biological stress response terminology: Integrating the concepts of adaptive response and preconditioning stress within a hormetic dose-response framework. Toxicol Appl Pharmacol 2007;222:122-128. [PubMed: 17459441]

Carlezon WA Jr, Duman RS, Nestler EJ. The many faces of CREB. Trends Neurosci 2005;28:436-445. [PubMed: 15982754]

Cuervo AM. Protein chaperones and cellular garbage removal mechanisms. Ageing Res Rev. 2007this issue

Frescas D, Valenti L, Accili D. Nuclear trapping of the forkhead transcription factor FoxO1 via Sirtdependent deacetylation promotes expression of glucogenetic genes. J Biol Chem 2005;280:2058920595. [PubMed: 15788402]

Gomez-Pinilla F. The influences of diet and exercise on mental health through hormesis. Ageing Res Rev. 2007 May 5;Epub ahead of print

Goodman Y, Mattson MP. Ceramide protects hippocampal neurons against excitotoxic and oxidative insults, and amyloid beta-peptide toxicity. J Neurochem 2006;66:869-872. [PubMed: 8592164]

Kline K, Lawson KA, Yu W, Sanders BG. Vitamin E and cancer. Vitam Horm 2007;76:435-461. [PubMed: 17628185]

Kojda G, Hambrecht R. Molecular mechanisms of vascular adaptations to exercise. Physical activity as an effective antioxidant therapy? Cardiovasc Res 2005;67:187-197. [PubMed: 15935334]

Korde AS, Pettigrew LC, Craddock SD, Maragos WF. The mitochondrial uncoupler 2,4-dinitrophenol attenuates tissue damage and improves mitochondrial homeostasis following transient focal cerebral ischemia. J Neurochem 2005;94:1676-1684. [PubMed: 16045446]

Lazarov O, Robinson J, Tang YP, Hairston IS, Korade-Mirnics Z, Lee VM, Hersh LB, Sapolsky RM, Mirnics K, Sisodia SS. Environmental enrichment reduces Abeta levels and amyloid deposition in transgenic mice. Cell 2005;120:701-713. [PubMed: 15766532] 
Lee JS, Surh YJ. Nrf2 as a novel molecular target for chemoprevention. Cancer Lett 2005;224:171-184. [PubMed: 15914268]

Li F, Mao HP, Ruchalski KL, Wang YH, Choy W, Schwartz JH, Borkan SC. Heat stress prevents mitochondrial injury in ATP-depleted renal epithelial cells. Am J Physiol Cell Physiol 2002;283:C917-926. [PubMed: 12176748]

Marini AM, Jiang X, Wu X, Pan H, Guo Z, Mattson MP, Blondeau N, Novelli A, Lipsky RH. Preconditioning and neurotrophins: a model for brain adaptation to seizures, ischemia and other stressful stimuli. Amino Acids 2007;32:299-304. [PubMed: 16998712]

Martin B, Mattson MP, Maudsley S. Caloric restriction and intermittent fasting: two potential diets for successful brain aging. Ageing Res Rev 2006;5:332-353. [PubMed: 16899414]

Masoro EJ. Overview of caloric restriction and ageing. Mech Ageing Dev 2005;126:913-922. [PubMed: 15885745]

Mathers J, Fraser JA, McMahon M, Saunders RD, Hayes JD, McLellan LI. Antioxidant and cytoprotective responses to redox stress. Biochem Soc Symp 2004;71:157-176. [PubMed: 15777020]

Mattson MP, Duan W, Chan SL, Cheng A, Haughey N, Gary DS, Guo Z, Lee J, Furukawa K. Neuroprotective and neurorestorative signal transduction mechanisms in brain aging: modification by genes, diet and behavior. Neurobiol Aging 2002;23:695-705. [PubMed: 12392775]

Mattson MP. Excitotoxic and excitoprotective mechanisms: abundant targets for the prevention and treatment of neurodegenerative disorders. Neuromolecular Med 2003;3:65-94. [PubMed: 12728191]

Mattson MP, Maudsley S, Martin B. A neural signaling triumvirate that influences ageing and age-related disease: insulin/IGF-1, BDNF and serotonin. Ageing Res Rev 2004;3:445-464. [PubMed: 15541711]

Mattson MP, Cheng A. Neurohormetic phytochemicals: Low-dose toxins that induce adaptive neuronal stress responses. Trends Neurosci 2006;29:632-639. [PubMed: 17000014]

Mattson MP, Meffert MK. Roles for NF-kappaB in nerve cell survival, plasticity, and disease. Cell Death Differ 2006;13:852-860. [PubMed: 16397579]

Mattson MP. Diet-induced hormesis and longevity. Ageing Res Rev. 2007this issue

Pong K. Ischaemic preconditioning: therapeutic implications for stroke? Expert Opin Ther Targets 2004;8:125-139. [PubMed: 15102554]

Radak Z. Exercise, oxidative stress and hormesis. Ageing Res Rev. 2007this issue

Raskin I, Ribnicky DM, Komarnytsky S, Ilic N, Poulev A, Borisjuk N, Brinker A, Moreno DA, Ripoll C, Yakoby N, O'Neal JM, Cornwell T, Pastor I, Fridlender B. lants and human health in the twentyfirst century. Trends Biotechnol 2002;20:522-531. [PubMed: 12443874]

Rattan SI. Hormesis and ageing. Ageing Res Rev. 2007this issue

Reddy L, Odhav B, Bhoola KD. Natural products for cancer prevention: a global perspective. Pharmacol Ther 2003;99:1-13. [PubMed: 12804695]

Riccioni G, Bucciarelli T, Mancini B, Di Ilio C, Capra V, D’ Orazio N. The role of the antioxidant vitamin supplementation in the prevention of cardiovascular diseases. Expert Opin Investig Drugs 2007; $16: 25-32$.

Satia-Abouta J, Patterson RE, Neuhouser ML, Elder J. Dietary acculturation: applications to nutrition research and dietetics. J Am Diet Assoc 2002;102:1105-1118. [PubMed: 12171455]

Scarmeas N, Stern Y. Cognitive reserve and lifestyle. J Clin Exp Neuropsychol 2003;25:625-633. [PubMed: 12815500]

Serrano F, Klann E. Reactive oxygen species and synaptic plasticity in the aging hippocampus. Ageing Res Rev 2004;3:431-443. [PubMed: 15541710]

Sohal RS, Weindruch R. Oxidative stress, caloric restriction, and aging. Science 1996;273:59-63. [PubMed: 8658196]

Sollott S. Conditioning ischemia hormesis. Ageing Res Rev. 2007this issue

Soobrattee MA, Bahorun T, Aruoma OI. Chemopreventive actions of polyphenolic compounds in cancer. Biofactors 2006;27:19-35. [PubMed: 17012761]

Staud R, Price DD. Mechanisms of acupuncture analgesia for clinical and experimental pain. Expert Rev Neurother 2006;6:661-667. [PubMed: 16734514]

Staud R. Thermal and nociceptive hormesis. Ageing Res Rev. 2007this issue 
Stumpf WE. Hormesis: a common mechanism of drug action. Ageing Res Rev. 2007this issue

Valko M, Izakovic M, Mazur M, Rhodes CJ, Telser J. Role of oxygen radicals in DNA damage and cancer incidence. Mol Cell Biochem 2004;266:37-56. [PubMed: 15646026]

Williams MT, Hord NG. The role of dietary factors in cancer prevention: beyond fruits and vegetables. Nutr Clin Pract 2005;20:451-459. [PubMed: 16207684]

Wu L, Noyan Ashraf MH, Facci M, Wang R, Paterson PG, Ferrie A, Juurlink BH. Dietary approach to attenuate oxidative stress, hypertension, and inflammation in the cardiovascular system. Proc Natl Acad Sci USA 2004;101:7094-7099. [PubMed: 15103025]

Yellon DM, Downey JM. Preconditioning the myocardium: from cellular physiology to clinical cardiology. Physiol Rev 2003;83:1113-1151. [PubMed: 14506302]

Young JC, Agashe VR, Siegers K, Hartl FU. Pathways of chaperone-mediated protein folding in the cytosol. Nat Rev Mol Cell Biol 2004;5:781-791. [PubMed: 15459659] 


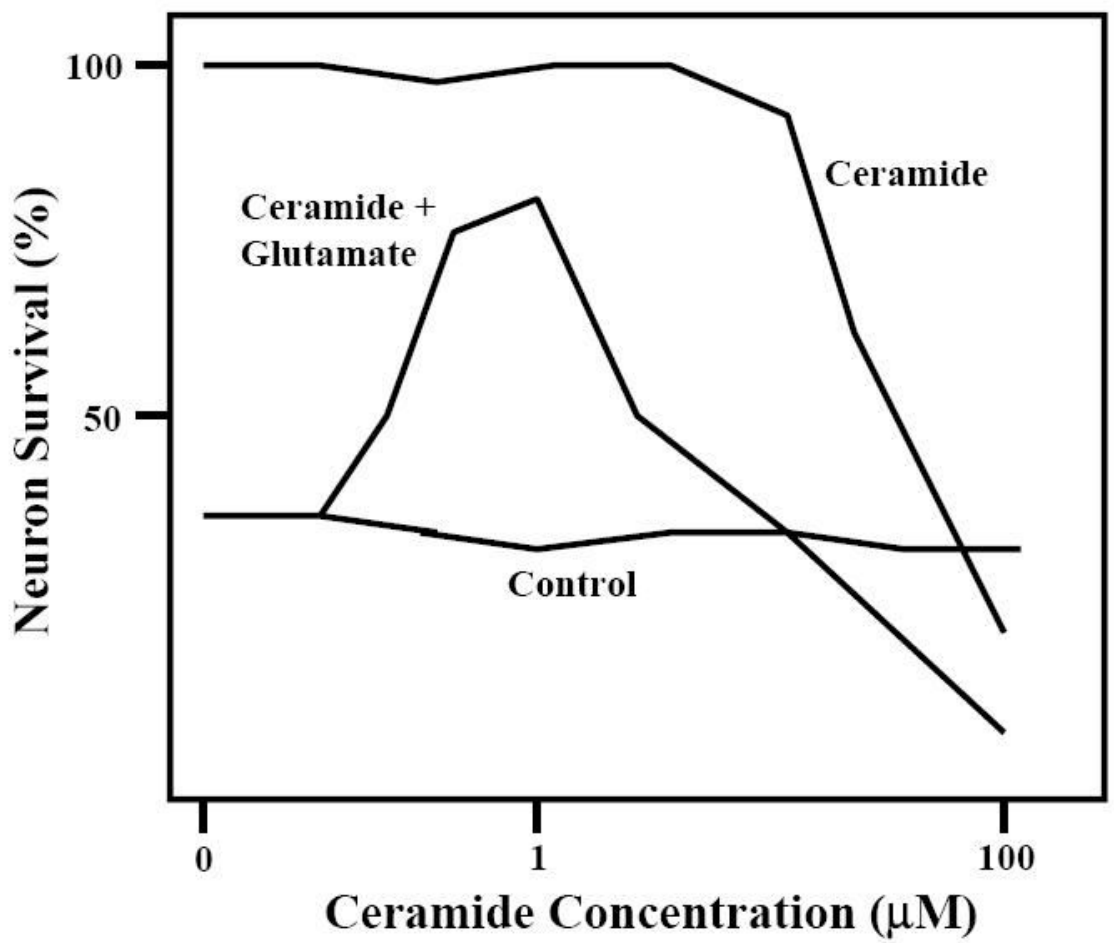

Figure 1.

Biphasic dose-response effect of the lipid mediator ceramide on nerve cells. Cultured rat hippocampal neurons were either pretreated for $20 \mathrm{~h}$ with the indicated concentrations of ceramide and then exposed to $10 \mathrm{uM}$ of the excitatory amino acid neurotransmitter glutamate for $24 \mathrm{~h}$, or were exposed to vehicle (control) or increasing concentrations of ceramide alone. Neuronal survival was then quantified. Modified from Goodman and Mattson (1996). 


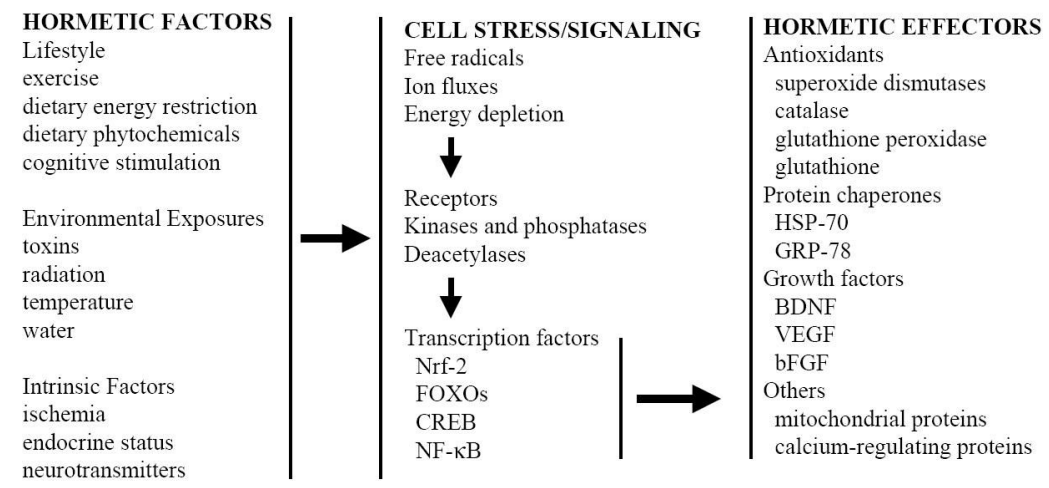

Figure 2.

The cellular and molecular information flow that mediates hormesis in organisms and cells. Hormesis can be initiated by exposure of organisms to extrinsic stimuli such as exercise, dietary modifications and environmental factors including heat and low doses of toxins. In addition, cellular hormesis can be induced by activation of intrinsic signaling pathways by (for example) changes in energy availability, hormones and neurotransmitters. Such hormetic exposures typically result in mild cellular stress involving free radical production, ion fluxes and increased energy demand. In response, adaptive stress response pathways involving kinases and deacetylases (for example) and transcription factors are activated in cells resulting in the production of hormetic effector proteins that protect cells against more severe stress. Examples of such stress resistance proteins include antioxidants, protein chaperones, growth factors, and proteins involved in the regulation of energy metabolism and cellular calcium homeostasis. 


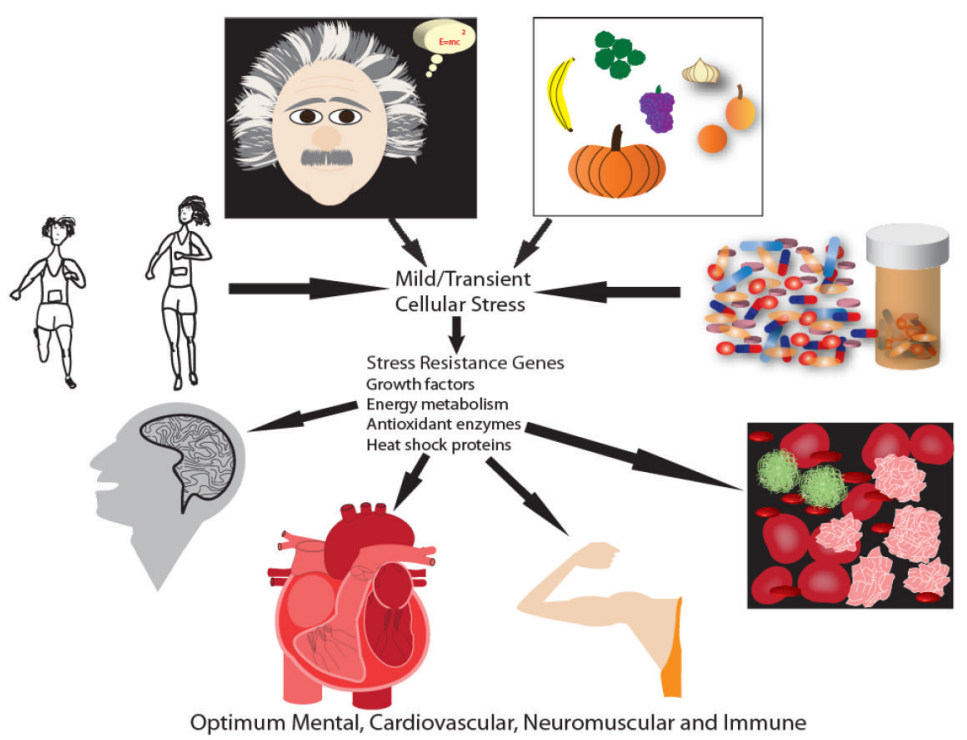

Figure 3.

Model for the involvement of hormesis in the beneficial effects of lifestyle, diet and drugs on health. 